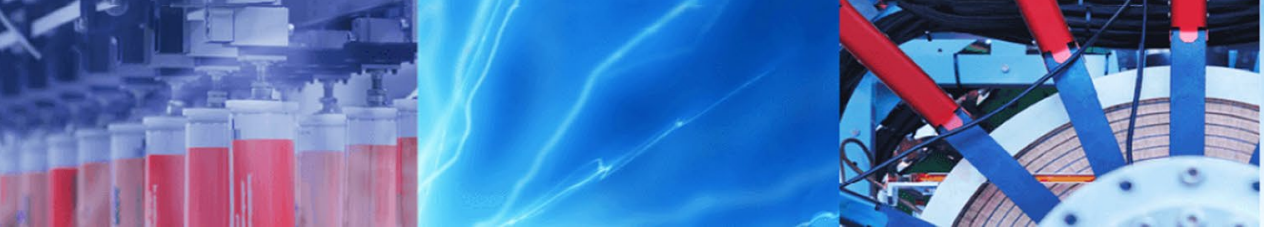

Research Article

\title{
Computational fluid dynamic for improving design and performance of an external loop airlift reactor used in electrochemical wastewater treatment
}

\author{
Rachid Bannari ${ }^{1} \cdot$ Youssef Hilali $^{2} \cdot$ Abdelhafid Essadki $^{3}$ (i) $\cdot$ Abdelfettah Bannari $^{4}$
}

Received: 12 June 2019 / Accepted: 17 October 2019 / Published online: 26 October 2019

(c) Springer Nature Switzerland AG 2019

\begin{abstract}
An innovative semi pilot reactor was designed for waste water treatment. It consists of an external loop airlift reactor used as electrochemical reactor in which electrocoagulation/electroflottation was performed to treat waste water. The computational fluid dynamic consisting of multiphase Eulerian-Eulerian formulation and a structured mesh was used in order to investigate the flow in two configurations of external-loop airlift reactors: a semi pilot airlift reactor (first configuration) and an improved external loop airlift reactor (second configuration). The simulation produced the experimental results for the first configuration and highlighted the weak efficiency in the case of continuous mode of the first configuration. The improved design was proposed to realize a total flotation of sludge in both modes: batch and continuous. The goal of this study is to illustrate the influence of different parameters in the flow pattern and the average liquid velocity. Interesting results were obtained by simulation showing that the electrodes position, hydrogen production related to the current intensity and the bubble diameter are the predominant parameters influencing the flow pattern in this reactor. The simulation concerning the improved second configuration exhibits that: (1) Average liquid velocity increases when the electrodes are positioned in depth (lower position in the riser). (2) The total flotation is obtained independently of the position of the electrodes while erosion of the flocks takes place for lower position of electrodes in the case of the first configuration. This constitutes an improvement in reactor performance in the case of batch mode. (3) Average liquid velocity decreases when the bubble diameter increases. The numerical procedure and simulation can be used as tools for the design and scale-up of external loop airlift reactors. An application is then presented to show the efficiency of electrocoagulation/electroflotation in removing color for textile effluent.
\end{abstract}

Keywords Computational fluid dynamics (CFD) - OpenFOAM - External-loop airlift reactor • Electrocoagulation (EC) . Electroflotation (EF)

\section{Introduction}

The need of purifying water for human consumption is more and more required. Thus, the management of the water cycle is essential for a sustainable water supply. An integrated solution is necessary to take into account all requirements and meet the global demand for water [1]. This may be achieved through the increased water reuse and recycling. Cleaning wastewater from industrial effluents before discharging is also a challenging work. In

\footnotetext{
$\triangle$ Abdelhafid Essadki, essadkiha@gmail.com | ${ }^{1}$ National School of Applied Sciences (ENSA), Ibn Tofail University, Kenitra, Morocco. ${ }^{2}$ Laboratoire d'Ingénierie et Matériaux (LIMAT), Faculté des Sciences Ben M'Sik, Université Hassan II de Casablanca, Sidi Othman, BP 7955, Casablanca, Morocco. ' ${ }^{3}$ aboratoire d'Environnement, Procédés et d'Energétique, Ecole Supérieure de Technologie de Casablanca, Université Hassan II de Casablanca, Km 7, Route El Jadida, BP 8012 Oasis, Casablanca, Morocco. ${ }^{4}$ Faculté des Sciences et Techniques, Université Sultan Moulay Slimane, Beni Mellal, Morocco.
} 
fact, innovative, cheap and effective techniques have to be developed. Chemical Coagulation-flocculation is one of the most used techniques for wastewater treatment [2] but certain drawbacks are induced by the presence of metal salts, acidification of the treated water and the large amount of sludge disposal. Biological treatment [3], advanced chemical oxidation such as $\mathrm{UV}, \mathrm{H}_{2} \mathrm{O}_{2}, \mathrm{O}_{3}$ [4-6], adsorption on adsorbent materials such as activated carbon [7] or membrane processes were effective, but in most cases very costly. An interesting alternative to these methods is electrocoagulation (EC). The electrocoagulation $(E C)$ process consists in producing, in situ, metal ions $\mathrm{M}^{\mathrm{n}}\left(\mathrm{Fe}^{2+}, \mathrm{Fe}^{3+}, \mathrm{Al}^{3+}\right)$ by the electrochemical dissolution of electrodes under the effect of an electric current. The metal cations produced allow, in a first step, coagulation and, in a second step, flocculation of the polluting particles. The separation of the aqueous mass is carried out by flotation or by decantation. The major complication that limits the development of studies on these techniques is the lack of equipment for its application as well as the models related to this technology. Mollah et al. [8] describe six typical device configurations for the industrial application of electrocoagulation.

The published papers deal in general with electrocoagulation processes at the laboratory scale. Recent studies used semi pilot reactors [9]. For textile wastewater treatment, Ahmed Samir et al. (2016) used a rotated anode in reactor having $10 \mathrm{~L}$ as capacity. The hexavalent chromium removal was treated by EC in a cylindrical column reactor with $4 \mathrm{~L}$ capacity [10]. Treatment of table olive processing wastewaters using electrocoagulation in laboratory and also in pilot-scale reactors was investigated [11].

The proposed design does not in general emerge from a rigorous study resulting from a simulation or a chemical engineering approach.

The objective in our study is to design an innovative reactor that allows the electrochemical treatment with an optimal cost based on simulation results for flotation effluent recovery.

For this, the airlift reactors can offer this opportunity because the sludge recovery can be achieved by flotation in the disengagement section. Thus, settling time constitutes a drawback for the pollutants as mentioned by Khorram et al. in their paper [12] in which even with a relatively high efficiency of color removal the settling required more time.

Airlift reactors are widely used in biological processes such as fermentation [13] and for culturing fungi [14] and biochemical waste water treatment and other chemical process. The use of this kind of reactor is based on higher fluid circulation and mass transfer, lower shear stress and the lower energy consumption. The specific energy input to disperse the gas and to allow a good mixing in the reactor can be achieved with much less energy by using the kinetic energy of the gas into reactor in the pneumatic driven gas-liquid.

Airlift reactor consists of two main compartments: the riser in which the gas is introduced and the other is named downcomer. Due to the density gradient of the fluid between the two compartments (aerated zone: riser and non-aerated zone: downcomer), a liquid movement is induced [15].

In most papers the industrial applications concern chemical and biochemical slow reactions $[15,16]$.

Many studies were focused on liquid circulation, mass transfer and gas holdups with two or three phase flow [17, $18]$, but never as an electrocoagulation (EC) cells, as far as we know.

Not long ago, and for the first time, external loop airlift reactor was used as electrochemical reactor [19]. It was especially used for Electrocoagulation (EC)-Electroflotation (EF) to treat the liquid effluents. In order to transform this reactor to an electrochemical one, the gas phase was not injected, but electrochemically-generated.

An application of ectrocoagulation/electroflotation in external loop airlift was performed showing high efficiency in removing color from synthetic and real textile wastewater by using aluminum and iron electrodes [20]. The defluoridation by EC was also performed in external loop airlift reactor [21]. In another previous paper the designed reactor was operated with continuous mode flow of liquid [22]. The inlet volumetric liquid flow-rate $Q_{L}$ varied between 0.1 and $2 \mathrm{~L} / \mathrm{min}$. A study of the residence time distribution (RTD) analysis of liquid phase has been performed. The liquid RTD is determined by means of the tracer response technique. The prior investigation [12] based on the residence time distribution measurements method had shown several troubles related to the liquid flow behavior. The inlet quantity is divided into two flows: one exit directly the rector by crossing the junction and the other cross the riser, the separator zone and the downcomer to exit. The percentage of flow that quits the reactor without reacting increased when the main flow increased and the current intensity decreased. The treated amount of effluent does not exceed $30 \%$ in continuous mode [22].

To resolve this problem, the Computational Fluid Dynamics (CFD) approach has been used, to validate the observed experimental anomalies and to propose an improvement of the airlift geometry and then the overall performance. The aim of this work is to investigate different hydrodynamic parameters in the previous airlift geometry and propose a new design to ensure a high treatment quantity of waste water.

CFD approach was used in internal loop airlift reactor, to produce cellulase by fungi $[14,23]$. In external loop airlift reactors CFD was used to study the hydrodynamic, mixing and mass transfer [24]. CFD simulation was also used 
to determine local gas holdup in an external loop airlift reactor [25]. A recent study has exposed the experimental and modeling aspects in airlift reactors [26]. Numerical simulation method for flow process in airlift reactors are reviewed, which are classified into two series, i.e. mathematical mechanism models and CFD models. The review provides a comprehensive analysis of such efforts, with critical discussion of published standpoints. Another recent paper presented experimental and numerical study of two-phase gas-liquid flows in the external-loop airlift reactor [27]. Both phases are calculated by solving the steady-state Reynolds-Averaged Navier-Stokes (RANS) conservation equations with the high Reynolds number $k-\varepsilon$ turbulence model. The aerodynamic drag, shear-lift and added mass forces, and the turbulent dispersion of the flow are considered.

As far we know no work has been investigated by using CFD in external loop airlift as electrochemical reactor in which gas phase is electrochemically generated.

In the present work, Navier-Stokes equations are coupled with $\mathrm{k}-\varepsilon$ model in order to take into account turbulence of the liquid flow. In this model, all the inter-phase forces (drag, lift and virtual masse) are used.

As the prime importance is to propose an adequate geometry in order to increase the quantity of water treatment with a good recirculation, only a mean bubble diameter is used. The population balance equations (PBE) need a high computational demand. In the next paper, the PBE equation will be used for the kinetic such as last work on fermentation [2].

\section{Materials and methods}

\subsection{Airlift reactors as EC-EF cells}

In a precursor study, Chisti et al. [16] developed a relationship between the induced overall liquid velocity and gas holdup difference between riser $\left(\varepsilon_{\mathrm{r}}\right)$ and downcomer $\left(\varepsilon_{\mathrm{d}}\right)$. This relationship is based on energy balance. The geometry and pressure drop were taking into account to give the following equation:

$U_{L r}=\left[\frac{2 g h_{D}\left(\varepsilon_{r}-\varepsilon_{d}\right)}{\frac{K_{T}}{\left(1-\varepsilon_{r}\right)^{2}}+\left(\frac{A_{r}}{A_{d}}\right)^{2} \frac{K_{B}}{\left(1-\varepsilon_{d}\right)^{2}}}\right]^{0.5}$

$\mathrm{K}_{\mathrm{T}}$ is the pressure drop coefficient in the riser and the separator sections and $K_{B}$ is the pressure drop coefficient in the downcomer and the junction; $A_{d}$ : cross-sectional area of the downcomer $\left(\mathrm{m}^{2}\right)$ and $A_{r}$ : cross sectional area of the riser $\left(m^{2}\right) ; h_{D}$ is the dispersion height.
Taking into account the mass balance on liquid phase, the superficial liquid velocity in the riser $\left(U_{L_{r}}\right)$ is deduced:

$U_{L r}=\frac{A_{d}}{A_{r}} U_{L d}$

The gas can be produced electrochemically by water electrolysis thus producing hydrogen at the cathode. The introduction of the electrodes (cathode and anode) in the riser section induced an overall liquid circulation because of the gas hold-up difference between the riser $\left(\varepsilon_{r}\right)$ and the downcomer $\left(\varepsilon_{\mathrm{d}}\right)$ in which $\varepsilon_{\mathrm{r}} \gg \varepsilon_{\mathrm{d}}$. The dispersion height and gas holdup in the riser depend on the axial position of electrodes in the riser.

In the case of aluminum electrodes, the reactions taking place at the electrodes are as follow:

At the anode, takes place oxidation:

$\mathrm{Al} \rightarrow \mathrm{Al}^{3+}+3 \mathrm{e}^{-}$

At the cathode, takes place reduction:

$2 \mathrm{H}_{2} \mathrm{O}+2 \mathrm{e}^{-} \rightarrow \mathrm{H}_{2}+2 \mathrm{OH}^{-}$

The bubbles of gas are produced in the vicinity of the cathode contributes strongly to the agitation of the medium. The bubble diameter is estimated at around 10-200 $\mu \mathrm{m}$ [19] depending on $\mathrm{pH}$ and current intensity.

The formation of metal hydroxides, metal oxy-hydroxides and polymeric hydroxides can destabilize the colloidal suspension, adsorb, neutralize or precipitate the pollutant species dissolved in the liquid. The flocs could be recovered by precipitation, filtration or flotation.

To realize a complete flotation, the hydrodynamic shear forces should be weak in the riser to avoid flock break-up and in the separator to limit break-up and erosion. This condition is reached with relatively low $U_{L d}$ values [19]. The design of an airlift reactor is mainly focused on hydrodynamics which is a key factor that plays a very important role in its performance.

\subsection{Correspondence between current intensity, gas flow-rate and bubble velocity}

The number and the size of bubbles are influenced by the current density [28]. Bubble behavior affects in turn the hydrodynamic regime of the separation process $[29,30]$.

Hydrodynamic parameters involve particularly the study of bubble rise velocity, bubble diameter effects.

According to the water electrolysis:

$\mathrm{H}_{2} \mathrm{O}+\mathrm{e}^{-} \rightarrow 1 / 2 \mathrm{H}_{2}+\mathrm{OH}^{-}$

One mole of $\mathrm{H}_{2}$ corresponds to 2 mol of electrons. Faraday's law can therefore be used to deduce the mass flow-rate as follows:

$\dot{m}_{G}=\frac{I M_{H_{2}}}{2 F}$ 
where $\mathrm{I}(\mathrm{A}), \dot{m}_{\mathrm{G}}(\mathrm{kg} / \mathrm{s}), \mathrm{M}_{\mathrm{H} 2}(\mathrm{~g} / \mathrm{mole})$ denotes respectively the current intensity, the mass flow rate of gas and the gas molar mass. $F=96,485(\mathrm{C} / \mathrm{mol})$ is the Faraday's constant and $\mathrm{M}_{\mathrm{G}}=2.016 \mathrm{~g} / \mathrm{mol}$ the molar mass of hydrogen gas $\left(\mathrm{H}_{2}\right)$. The volume flow-rate can be expressed as follow:

$Q_{G}=\frac{\dot{m}_{G}}{\rho_{H_{2}}}$

$\rho_{\mathrm{H} 2}=0.085 \mathrm{~kg} / \mathrm{m}^{3}$ is the hydrogen density.

The superficial gas velocity $\left(U_{g r}\right)$ is obtained by dividing the volume flow-rate to the surface of the electrode $\left(S_{e}\right)$ :

$U_{g r}=U_{g}=\frac{Q_{G}}{S_{e}}$

Table 1 correspondence current intensity-superficial gas velocity

\begin{tabular}{ll}
\hline$I(A)$ & $U_{g}(\mathrm{~cm} / \mathrm{s})$ \\
\hline 1 & 0.0007 \\
2 & 0.0014 \\
10 & 0.007 \\
16 & 0.0112 \\
20 & 0.014 \\
25 & 0.0175 \\
\hline
\end{tabular}

The relationship between superficial gas velocity and current intensity can be deduced:

$U_{g}=\frac{I M_{H 2}}{2 F \rho_{G} S_{e}}$

The surface of the electrode $\left(S_{e}\right)$ is chosen to be equal to $175 \mathrm{~cm}^{2}$ as in the previous paper [19].

Table 1 shows the correspondence between the superficial gas velocity and the current intensity.

\subsection{Hydrodynamic model}

The CFD model was developed and validated in our previous works [14, 31]. The flow model, gas holdup equations are based on Navier-Stokes equations for the Eulerian-Eulerian multiphase approach (Table 2). In the present work, all the inter-phase forces (drag, lift and virtual masse) are considered (see Table 2).

In order to take into account turbulence of the underlying flow, the same equation of $k-\varepsilon$ [31] is used. Indeed, we are working with a modified high Reynolds number. The drag of the bubbles motion causes a small eddies and minimum turbulent channel which affect the overall velocity distribution. In our case the presence of the walls (reactor walls and anode/cathode walls) where the viscous effects dominate because of the viscous sub-layer so the

Table 2 Governing equations and interphase forces used in this work

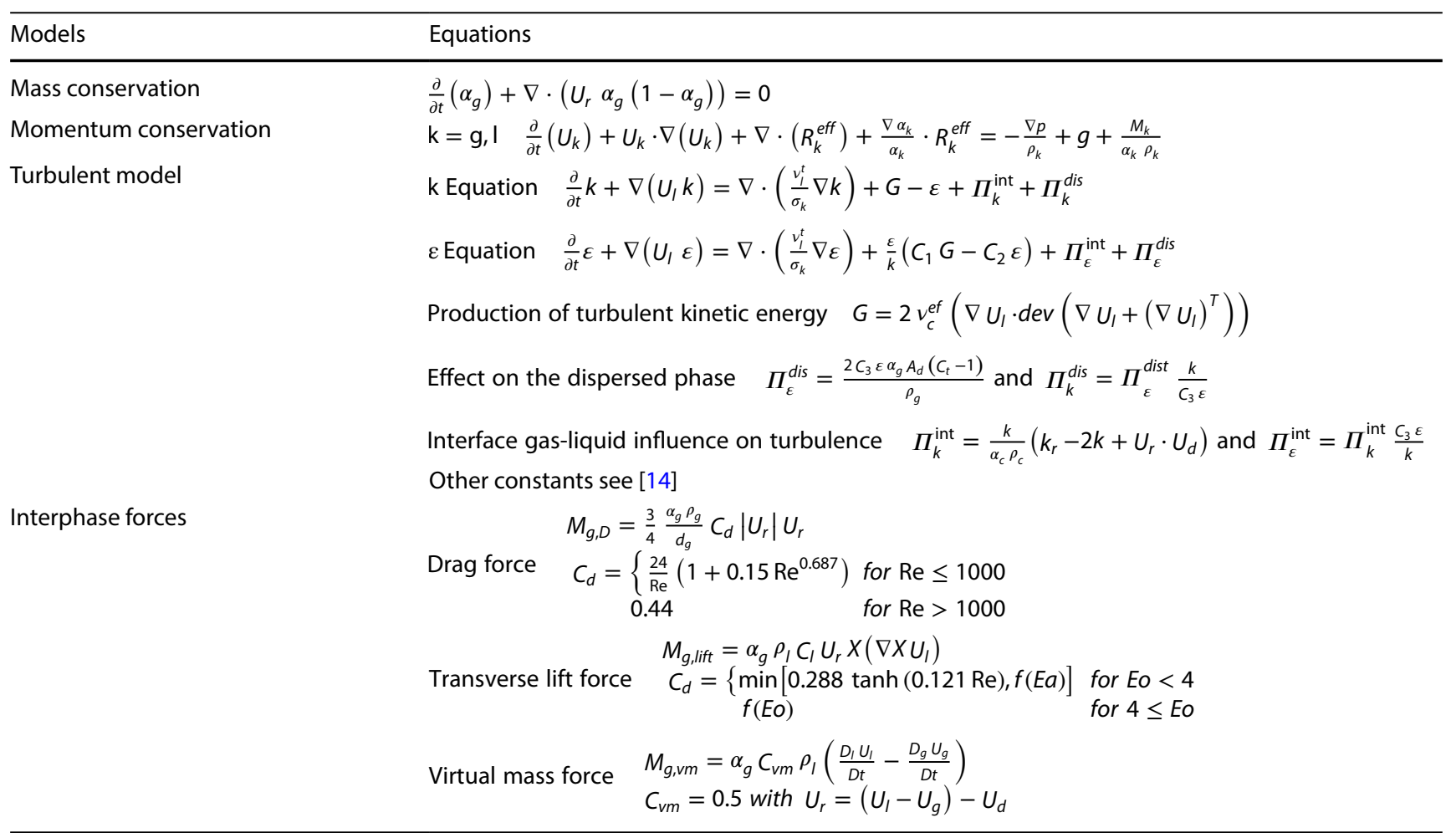


turbulence in these regions became more important and the velocity distribution more affected. After some distance, small chaotic oscillations begin to develop in the boundary layer and the flow begins to transition to turbulence, eventually becoming fully turbulent. The most $k-\omega$ based models are low Reynolds number models and a standard $k-\varepsilon$ model and other commonly encountered $k-\varepsilon$ models are not low Reynolds number models. However, in our case, it supplemented with so-called damping functions that give the correct limiting behavior. They are then known as modified Reynolds number k- model which often gives a very accurate description at low Reynolds number and accurate description of the boundary layer because it improves near-wall stability

\subsection{CFD package}

In the present work, the Open source Field Operation and Manipulation (Open FOAM) C++ libraries are used as a free source. In previous works, this aspect is deeply described $[14,31]$.

The governing equations (Navier-Stokes equations) are discretized by the finite volume method that is based on the Weller approach [32]. This approach has proved very stable in both transient and steady state modes.

The non-linearity of the Navier-Stokes equations requires efficient methods. Indeed, these equations are quasi-nonlinear and weakly coupled. Nonlinearity is overcome by an iterative calculation. By choosing a stable numerical scheme, the errors introduced by the initial solution are damped and the procedure will converge easily to an acceptable final solution. The coupling problem is manifested by the appearance of velocity and pressure variables. The pressure gradient which appears as a source term in these equations plays the role of the driving force of flow.

One of the algorithms used is the SIMPLE algorithm. An initial pressure field is assumed and is injected into the momentum equation. The system is resolved to find an intermediate velocity field. The continuity equation is transformed to become a pressure correction equation. It is resolved to find a pressure correction that will reinject a new pressure in momentum equations. The cycle is repeated as many times as necessary until a zero pressure correction is obtained, a sign of the convergence of the algorithm.

PISO (Pressure Implicit with Splitting of Operators) is a procedure proposed by ISSA [33]. It is used to couple pressure to velocity via the continuity equation. The pressure equation is derived into a semi-discretized form of the momentum equation. This algorithm was initially developed for non-iterative calculations of non-stationary and compressible flows. It has been successfully adapted for iterative calculations of stationary problems. The algorithm is similar to SIMPLE with an improvement that consists of making two successive corrections instead of one [33].

The sequence of the solution procedure is summarized in Fig. 1. For the non-orhogonal mesh, Open Foam proposes an iterative procedure to correct the face fluxes by separating the flux into two parts known as the orthogonal and non-orthogonal distribution [34].

The PBE was implemented in Open Foam as new solver and adapted to Two Phase Euler Foam handles incompressible two-phase flows [35] with the modification of $k-\varepsilon$ equation as explained previously in our last paper [36]. In this work, the PBE equations are not solved as we need to study the influence and the effect of bubble diameters on the behavior of the circulation and the result comparing with the experimental data.

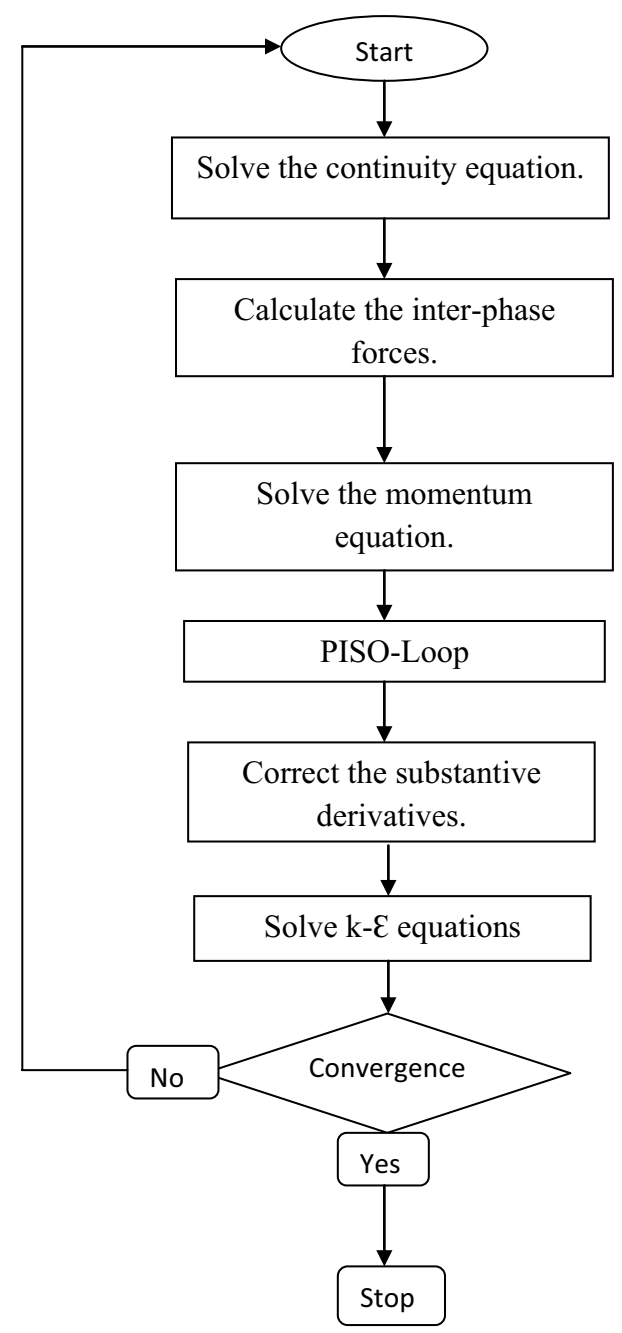

Fig. 1 Numerical solution procedure 


\subsection{Geometries: First configuration and Proposed design for a new configuration}

The first configuration consists of an external-loop airlift reactor. The reactor geometry is illustrated in Fig. 2. The detail was described in a previous work [19]. Figure 3 shows a photo of the reactor in which the electrocoagulation/electroflotation was performed to eliminate real textile effluent. The pollutant is recovered in floated sludge.

The simulation is carried out for this configuration to find the experimental results when this reactor is functioning with continuous mode. Thus, the residence time distribution study [9] revealed the quantity of the liquid that quits the reactor without reacting, is almost the same (between 70 and 90\%).

A new reactor was then designed as a new external loop airlift reactor to overcome the problems encountered in the first configuration. The detail of the reactor is shown in Fig. 4. The design of this reactor was based on the simulations results as we can see later (Sect. 3.2).

\subsection{Numerical solution and boundary conditions}

In this paper, a QUICK scheme with deferred-correction method for the convection term discretization of gas holdup is adopted. The QUICK scheme takes the second order derivative into account, but ignores the third order
Fig. 2 External loop airlift reactor (20 L) [6]. (1: downcomer section; 2 : riser section; 3 : conductivity probes; 4 : conductimeter; 5: analog output/ input terminal panel (UEIACkit; 7: data acquisition system; 8: electrodes; 9: separator; 10: electrochemically-generated bubbles) 1585-1); 6: 50-way ribbon cable

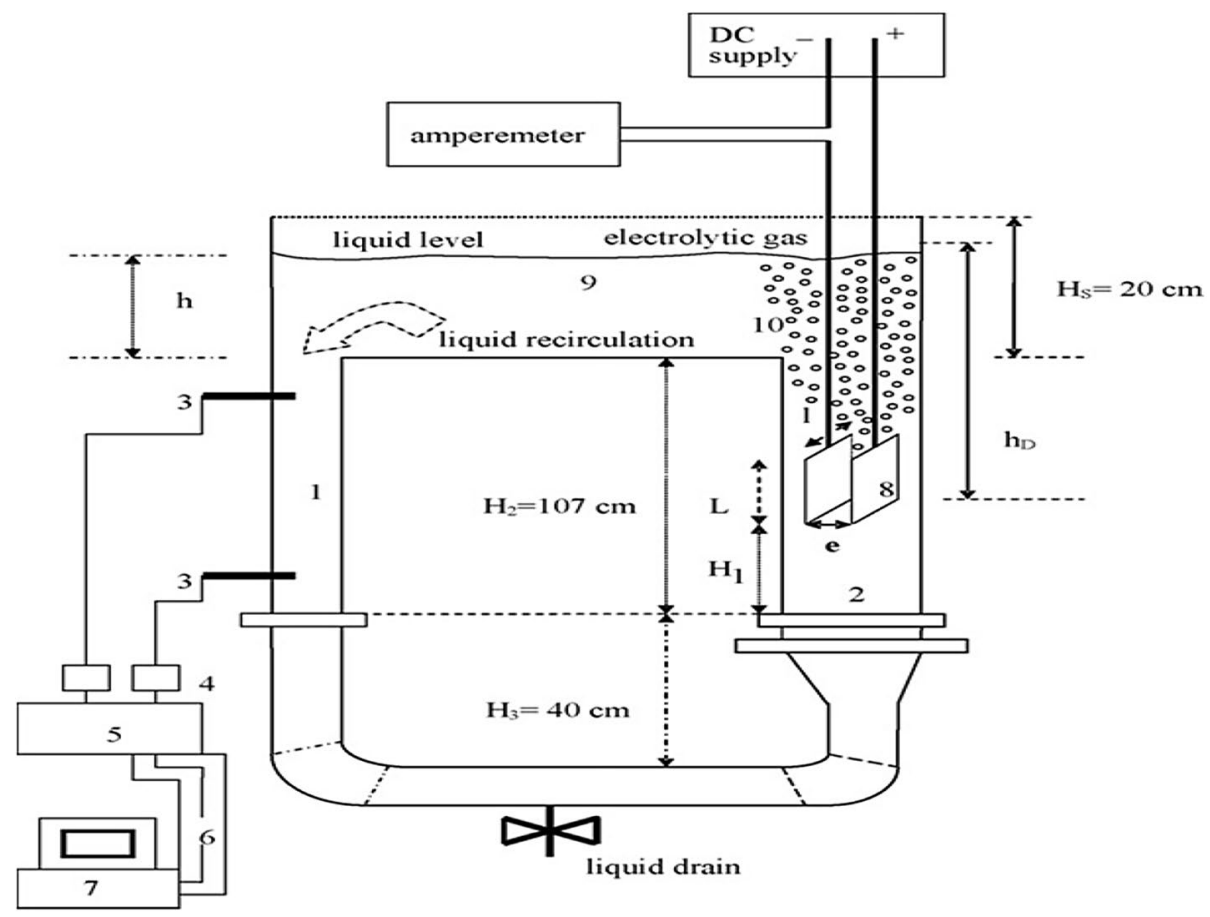

Fig. 3 Photos showing decolourization by EC in external loop airlift reactor of real textile dye

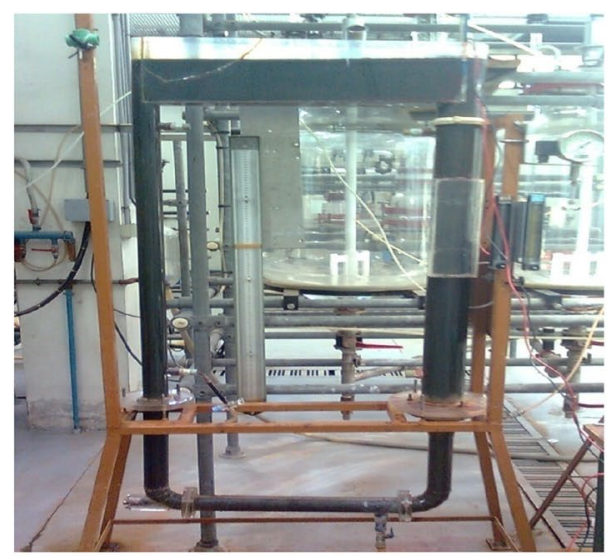

Textile effluent before treatment $(C O D=3570 \mathrm{mg} / \mathrm{L})$

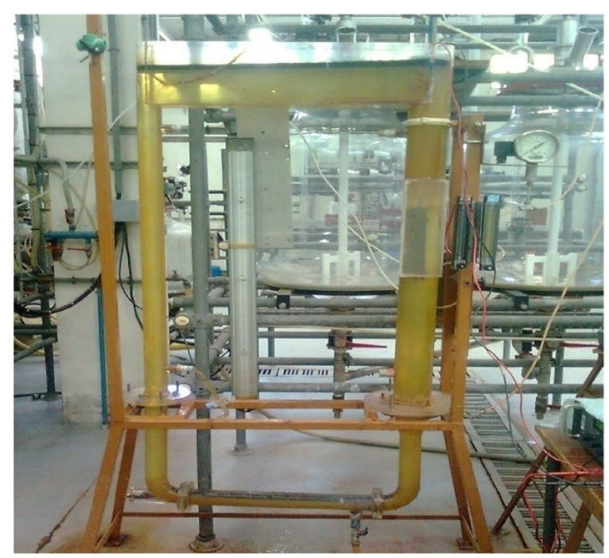

Textile effluent after 15 minutes EC treatment 


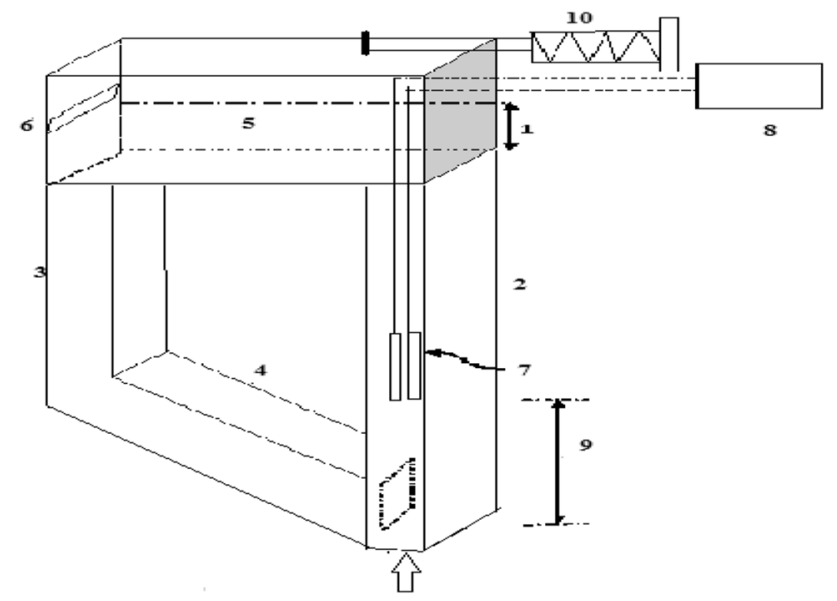

Fig. 4 Improved External-loop airlift reactor: 1: level of the effluent in the separator, 2: riser section, 3: downcomer section, 4: connecting column, 5: separation section, 6: slot, 7: electrodes, 8: generator, 9: $\mathrm{H}_{1}$ : electrodes position, 10: scraping system

derivative. The second order upwind scheme is adopted for all the other equations. The calculations are carried out for the two geometries presented above.

The problem of the precision of the results is related to the number of cells in the mesh which should be sufficient for an exact description of the phenomenon. On the other hand an excessive number of cells can cause a divergence of the program. In our case, tests were made to study the influence of the mesh on the numerical results. The adequate mesh was found ensuring convergence and accuracy. Concerning the numerical stability, a time step of $10^{-4} \mathrm{~s}$ was the appropriate time.

The boundary conditions are of considerable importance. They determine the actual profile of the flow.

A no-slip boundary is used and the standard wall functions are adopted for all phases at the solid wall [37].

At the inlet, the Dirichlet condition is adopted to the gas in which the gas fraction is equal to 1 .

The inlet conditions for the turbulent kinetic energy and the dissipation rate are estimated by:

$k=\frac{3}{2}\left(U_{\text {inlet }} l\right)^{2}$

where $/$ is the turbulent intensity.

$\varepsilon=C_{\mu}^{0.75} \frac{k^{1.5}}{0.07 L}$

where $L$ is the characteristic length of the apparatus.

The Neuman condition was used for outflow boundary of the rector. The free surface is considered as free for liquid phase with zero normal velocity as suggested by Mudde and Van Den Akker [38].
The imposed superficial gas velocity, in the electrodes cell area, is presented on Table 1. The electrodes faces mesh use one as hydrogen volume fraction and zero for the liquid value.

The adopted method is dictated by the structure of the matrix. For symmetric matrices, the preconditioned conjugate gradient (ICCG) is adopted while for asymmetric matrices the preconditioned bi-conjugated gradient (PBICG) is the most appropriate [34]. ICCG with tolerance equal to $10^{-8}$ is used for pressure, while PBICG is used for velocities, dissipation, turbulent kinetic energy and phase.

\subsection{Materials for experiments}

Absorbance was measured every 10 min to follow the efficiency evolution. Colour removal efficiencies $\left(Y_{\mathrm{COL}}\right)$ was expressed as follows:

$Y_{\mathrm{COL}}(\%)=\frac{A_{0}-A}{A_{0}}$

In Eq. (12), $A_{0}$ and $A$ are respectively the initial absorbance and the absorbance at a certain time.

Spectrophotometer (UV-Visible spectrometer Helios $\gamma$, type Gamma) was used to determine dye concentration by its absorbance characteristics in the UV-vis range $(200-800 \mathrm{~nm})$. The maximum intensity of absorbance was obtained by using the wavelengths $\lambda_{\max }=436,525$ and $620 \mathrm{~nm}$ covering the absorbance of various types constituting the mixture. Initial $\mathrm{pH}$ measured with a $\mathrm{pH}$ meter (PHM 220 Radiometer analytical). Conductivity was determined by a conductivity meter ("Cyberscan 510-cond" "Conductimeter Consort K 120").

Real wastewaters were provided from ITEX, Textile industry (Casablanca, Morocco). It consists of dispersee dye containing Yellow Terasil 4G, Red disperse and Blue Terasil $150 \%$. The working temperature is $20^{\circ} \mathrm{C}$.

\section{Results and discussion}

\subsection{First configuration (O.D.A) with continuous mode}

The first step of the computation lies in the development of a mesh which ensures the convergence of the numerical procedure, and which is able to capture the different variations of the parameters in the computational domain. In addition, a mesh must ensure the independence of the solution of the refinement (increase of the number of meshes). In our study several meshes were tested, with different meshing scheme, proposed by Gambit software, near the walls. Figure 5 represents the study of 


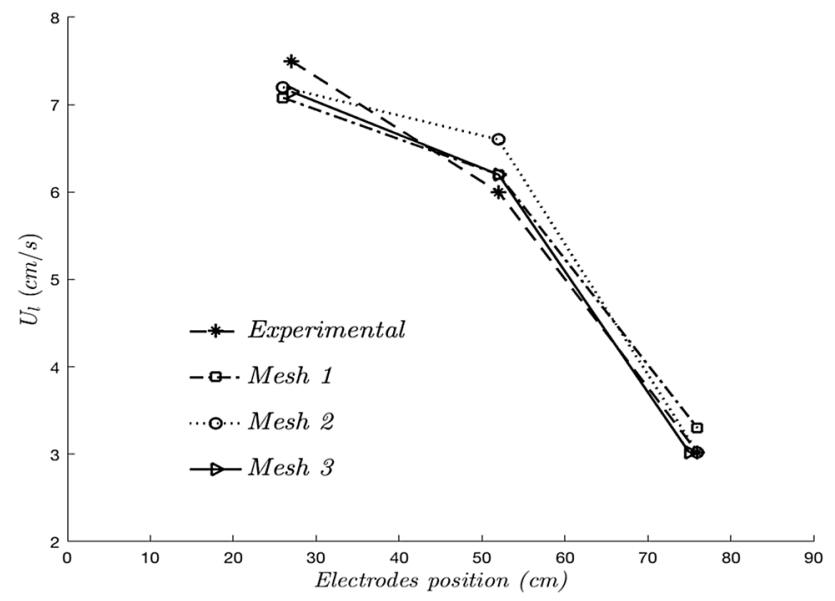

Fig. 5 Influence of the mesh on the numerical results

three different meshes (mesh $1=250,514$ elements, mesh $2=180,634$ elements and mesh $3=154,605$ elements). It shows that the numerical results of the induced liquid velocity versus the electrodes position are independent of the obtained results comparing with experiment results.

The mesh was chosen to ensure a minimum number of cells and provides efficiency in computing with good accuracy, and a short time of calculation. The mesh is fine in the zone of high velocity gradients (near the electrodes and walls). Figures 6 and 7 show a view of the used mesh which consisting of 154,605 elements. For the non-orthogonal cells, we use an iterative procedure to correct the face fluxes by separating the flux into two parts known as the orthogonal et non orthogonal distributions as proposed by Jasak [22].

The previous study [12] revealed that a large amount of effluent to be treated exit directly to the outlet without reacting in the riser section. The goal of numerical simulation is to verify this result and find possible solutions.

To test the influence of the position of the liquid outlet on the hydrodynamic, two positions were tested as indicated in Figs. 6 and 7. An example of simulation is undertaken, for a current intensity with $2 \mathrm{~A}$ value which induced a superficial gas velocity of $14.10^{-4} \mathrm{~cm} / \mathrm{s}$. The input liquid flow rate was chosen to be equal to $2 \mathrm{~L} / \mathrm{min}$.

The first position corresponds to the real position of the liquid outlet [12] of the reactor functioning with continuous mode. The second position corresponds to an upper position of the liquid outlet. Figure 8 shows the velocity vectors of the liquid medium phase.

As observed in Fig. 8 for both outlet positions, a large amount of the liquid quits the rectors without reacting in the riser section in both cases. The troubles observed by using the Residence Time Distribution (RTD) [12] analysis were confirmed by the simulation results. The efficiency defined in continuous mode, as the percentage of the main flow that crosses the riser section (participating in electrochemical reaction) is weak in this kind of configuration.

The average liquid velocity in the downcomer, $\left(U_{\mathrm{Ld}}\right)$ was measured using the conductivity tracer technique [12]. Two conductivity probes placed in the downcomer section were used to record the tracer concentration
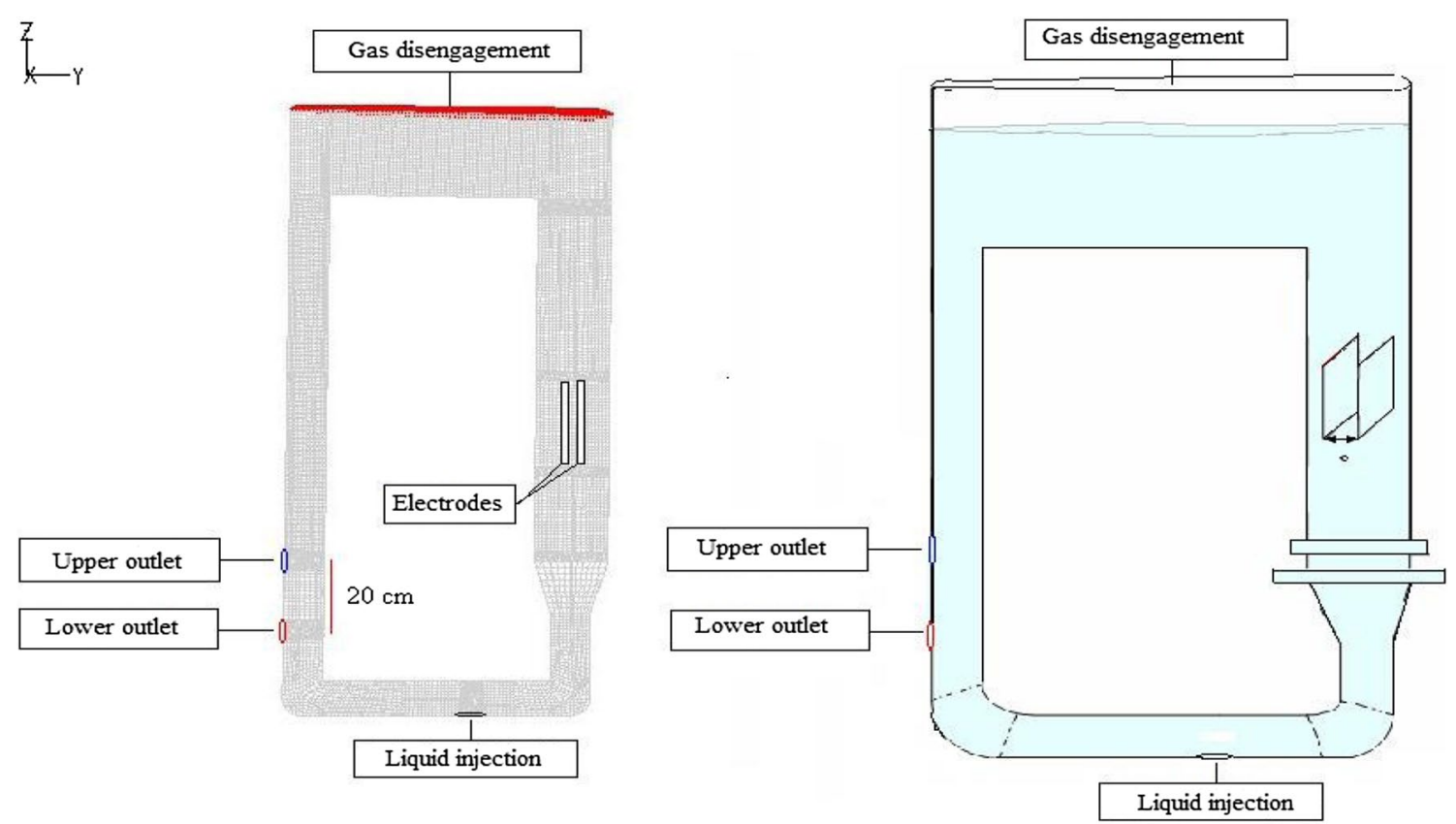

Fig. 6 Initial geometry and corresponding mesh for the O.D.A reactor with different outlet positions 
Fig. 7 The mesh of O.D.A geometry with two outlet positions

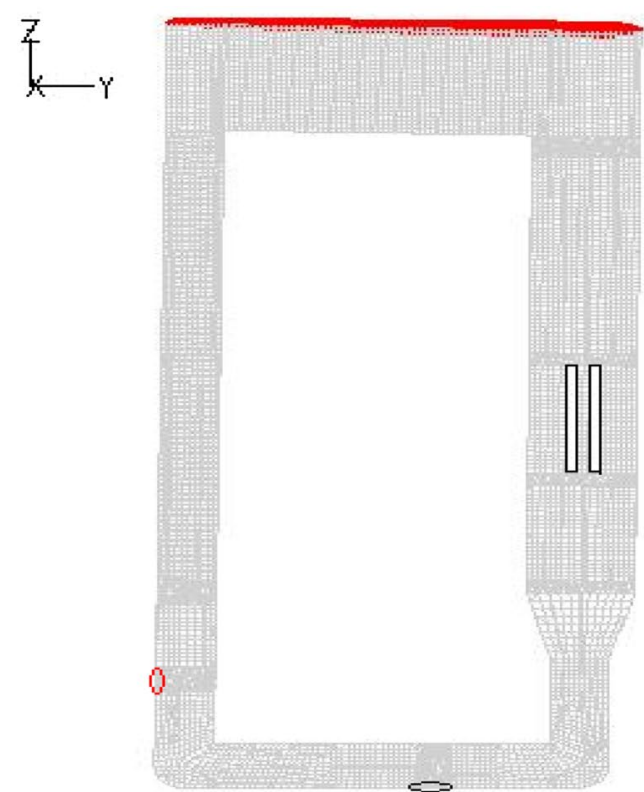

Case 1 : Mesh of the first reactor with opened lower output and closed upper output.

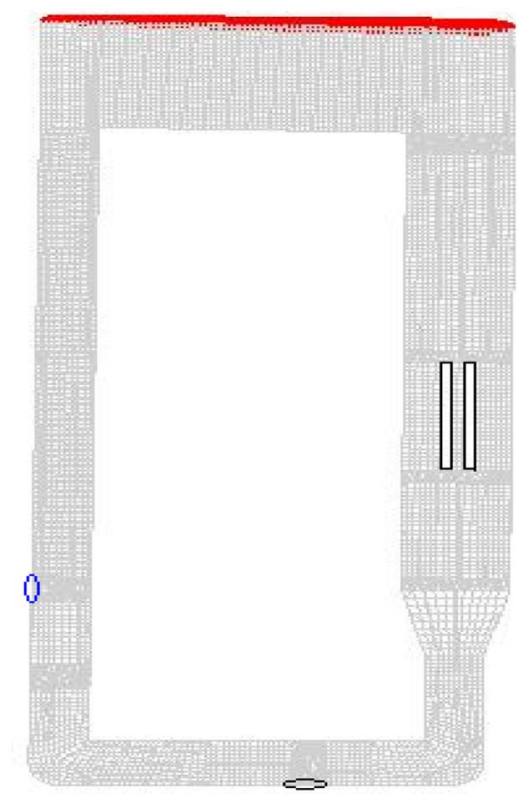

Case $2:$ Mesh of the first reactor with closed lower output and opened upper output. resulting from the injection of $5 \mathrm{~mL}$ of a saturated $\mathrm{NaCl}$ solution at the top of the downcomer using a data acquisition system. Liquid velocity was estimated using the ratio of the mean transit time between the tracer peaks detected successively by the two electrodes and the distance between the probes.

The simulation results give the same tendency. The quantity of the liquid that quits the reactor without reacting, obtained by averaging the liquid velocities in junction section is almost the same (between 70 and $90 \%$ ) as confirmed by the experimental results.

The average of velocity is averaged according to the section area:

$U_{L d}=\frac{1}{A_{d}} \int u(r, \theta) r d r d \theta$

The flow pattern exhibits a turbulence flow as indicated by the vector representation of the liquid velocity field.

The flow pattern is the same for both cases in different compartment of the external loop airlift reactor (Fig. 8a, b). The calculation of the average liquid velocity in downcomer section shows slight different values for the two cases. Thus, the average liquid velocity reaches $1.125 \mathrm{~cm} / \mathrm{s}$ in the case of upper outlet, whereas it reaches $1.28 \mathrm{~cm} / \mathrm{s}$ in the case of lower position. The average liquid velocity decreases as the outlet moves upwards.

The experimental values of liquid velocity are around $1 \mathrm{~cm} / \mathrm{s}$ in the case of continuous mode as found in the
RTD analysis [12]. The velocity fields show relatively mild recirculation eddies.

The simulation indicated also that the gas is present only on the riser and disengagement sections as shown on Fig. 9. The same results are obtained for the two cases.

\subsection{Second configuration (N.D.A) with batch mode}

The external loop airlift reactor has an operating volume of $20 \mathrm{~L}$. As in the first configuration, the study of different meshes was studied. It shows also that the numerical results of the induced liquid velocity versus the electrodes position are independent of the obtained results comparing with experiment results. The computational domain for the model of the reactor is shown in Fig. 10. It contains 492,171 cells with 165,571 hexahedral cells, 170,058 tetrahedral cells, and 156,542 pyramidal cells.

The purpose of the study of the functioning of this batch reactor is the evaluation of the impact of the position of the electrodes and bubble diameter on the superficial liquid velocity and gas holdups for a given current intensity.

\subsubsection{Influence of electrodes position}

The new external-loop airlift reactor is used as a batch reactor. The current intensity is $2 \mathrm{~A}$ corresponding to $14.10^{-4} \mathrm{~cm} / \mathrm{s}$ as a superficial gas velocity. The bubble diameter is chosen to be $0.2 \mathrm{~mm}$. Three positions of electrodes 


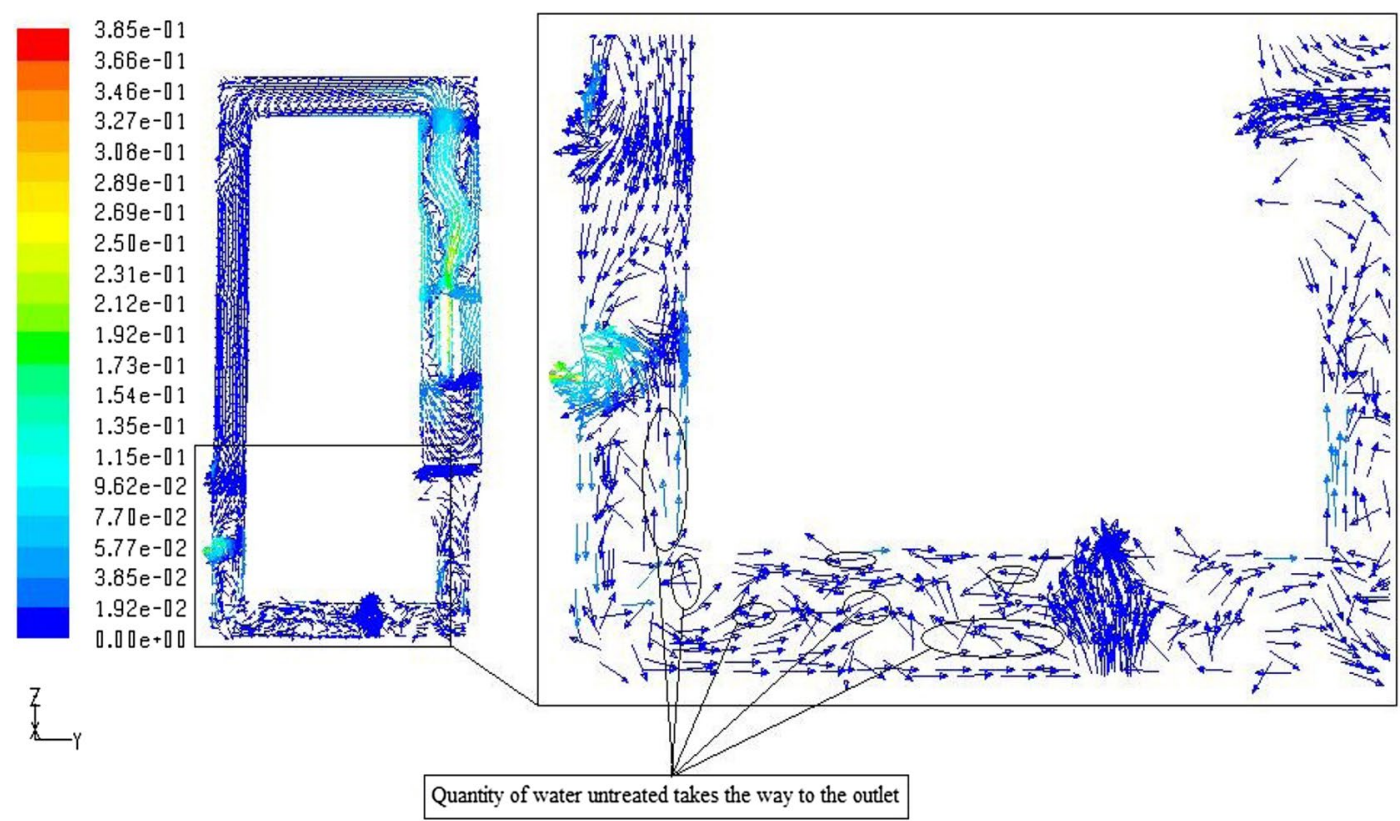

(a)

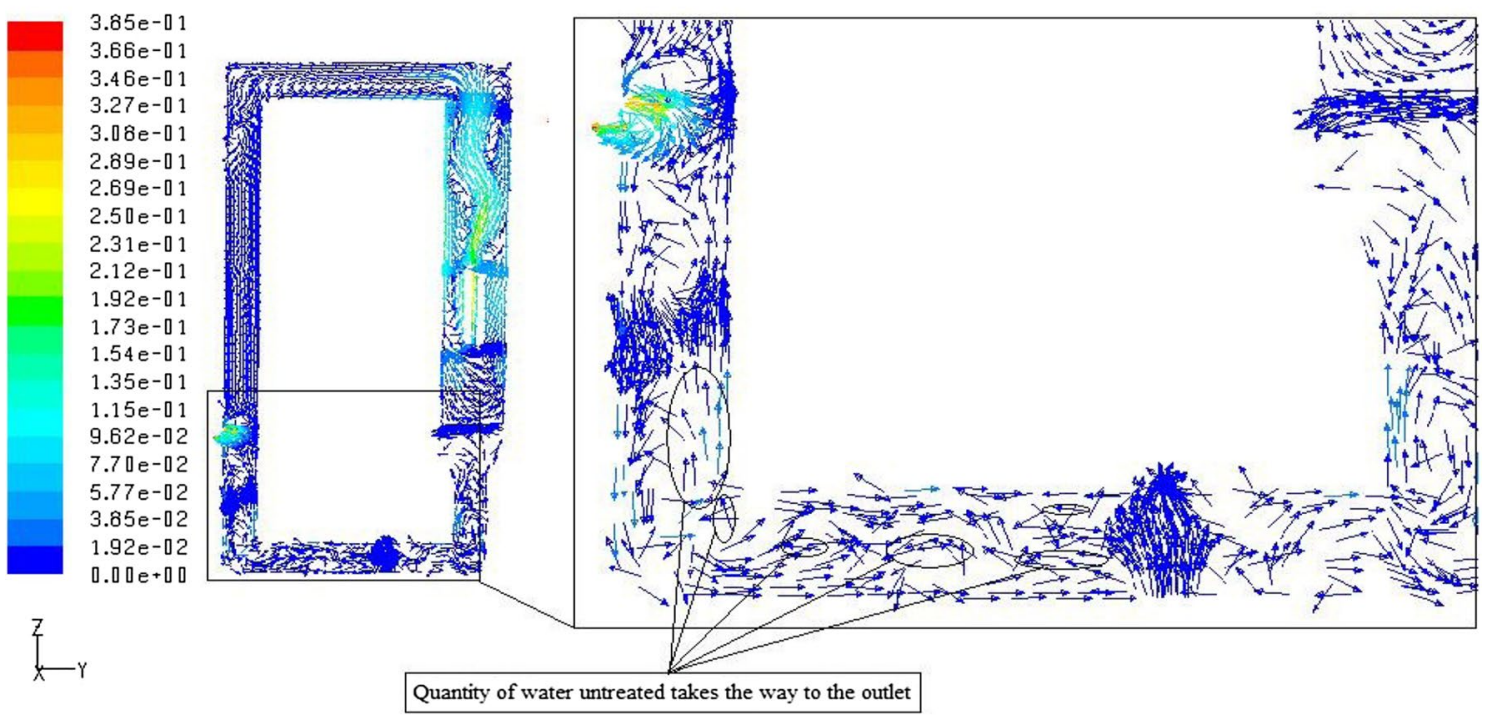

(b)

Fig. 8 Liquid velocity field for: O.D.A reactor: Lower position of the outlet: O.D.A reactor: Upper position of the outlet

were chosen: lower, middle and upper positions as indicated in Table 3 indicates the exact position.

Figure 11 shows that the values obtained by simulation are very close to the experiments results showing that the average liquid velocity increases when the electrodes are positioned in depth. This result is in perfect accordance with the prevision of Eq. (1) in which the liquid velocity increased with the dispersion height $h_{D}$ i.e. when the electrodes occupy lower position in the downcomer.

Figure 12 shows liquid velocity vectors. A maximum of liquid velocity is obtained near the electrodes. Contrary to the average value, the maximum value of the liquid velocity is almost the same for the three positions of the electrodes $(31.1 \mathrm{~cm} / \mathrm{s})$. The maximum value is between five to ten times the values of the average liquid velocity depending on the electrodes position (Table 4).

The distribution of liquid velocity field is more presented in term of magnitude as indicated in Fig. 13.

The average liquid velocity is relatively high in the area located just above the electrodes, which is due to the upward movement of the hydrogen bubbles leading to high liquid velocity in this region. The liquid velocity is also 
Fig. 9 Distribution of the gas volume fraction in the ODA reactor

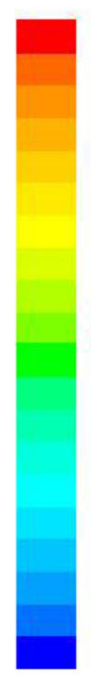

5.00e-01

$4.75 \mathrm{e}-01$

$4.50 \mathrm{e}-01$

$4.25 e-01$

$4.00 \mathrm{e}-01$

$3.75 e-01$

$3.50 \mathrm{e}-01$

$3.25 e-01$

$3.00 \mathrm{e}-01$

$2.75 e-01$

$2.50 e-01$

$2.25 \mathrm{e}-01$

2.00e-0 1

$1.75 \mathrm{e}-01$

$1.50 \mathrm{e}-01$

$1.25 e-01$

$1.00 e-01$

$7.50 \mathrm{e}-02$

$5.00 \mathrm{e}-02$

$2.50 \mathrm{e}-02$

$0.00 \mathrm{e}+00$
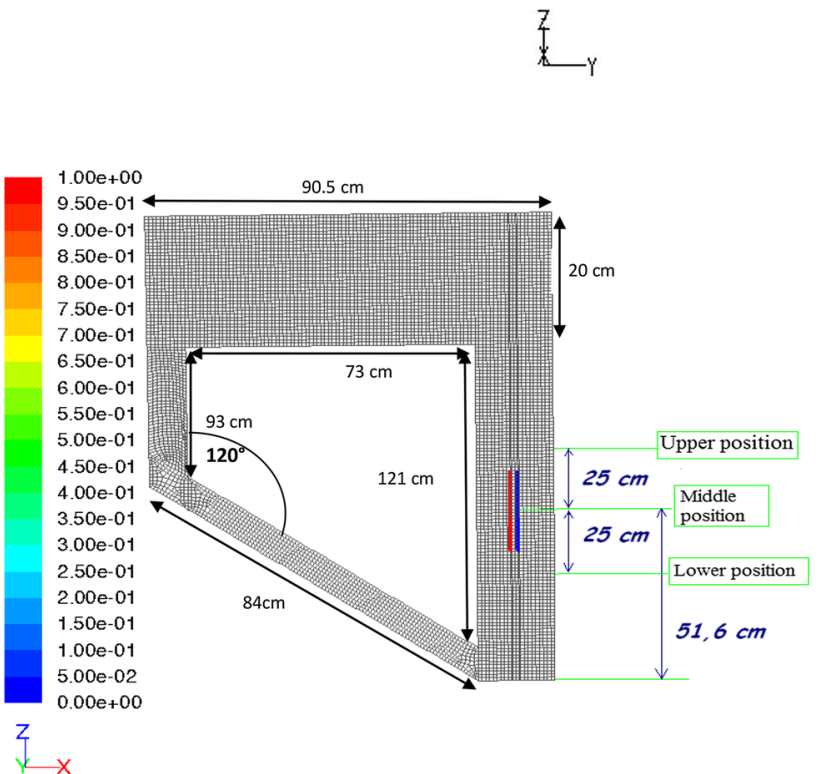

Fig. 10 Structured mesh: 165,571 cells in N D A reactor

Table 3 z Coordinates of electrodes (New design of external airlift)

\begin{tabular}{llll}
\hline & $\begin{array}{l}\text { Lower position } \\
(\mathrm{cm})\end{array}$ & $\begin{array}{l}\text { Middle position } \\
(\mathrm{cm})\end{array}$ & $\begin{array}{l}\text { Upper position } \\
(\mathrm{cm})\end{array}$ \\
\hline Coordinates & 26.6 & 51.6 & 76.6 \\
\hline
\end{tabular}

relatively high in the case of the low position of the electrodes as indicated by the presence of green color.

Figure 14 represents a photo showing the electroflotation of the sludge. This indicates that a complete flotation of sludge is obtained allowing a high value of removal efficiency (detail in Sect. 3.3).

The total flotation of sludge is obtained for the three positions of the electrodes, contrarily to the first
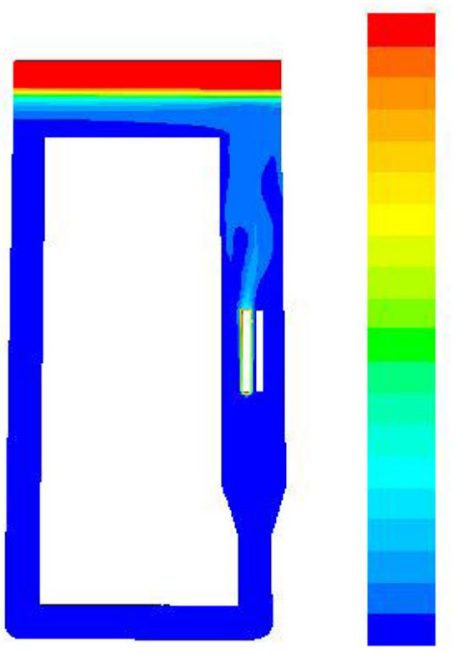

$5.00 \mathrm{e}-01$

$4.75 e-01$

$4.50 e-01$

$4.25 e-01$

$4.00 e-01$

$3.75 e-01$

$3.50 \mathrm{e}-\mathrm{Q} 1$

$3.25 e-01$

3.0 0 e- 1

$2.75 e-01$

$2.50 e-01$

$2.25 e-01$

2.0 $0 e-01$

$1.75 e-\square 1$

$1.50 \mathrm{e}-\mathrm{Q} 1$

$1.25 e-\square]$

$1.00 \mathrm{e}-\mathrm{Q} 1$

$7.50 \mathrm{e}-\mathrm{02}$

$5.00 \mathrm{e}-02$

$2.50 \mathrm{de}-\mathrm{ac}$

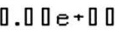
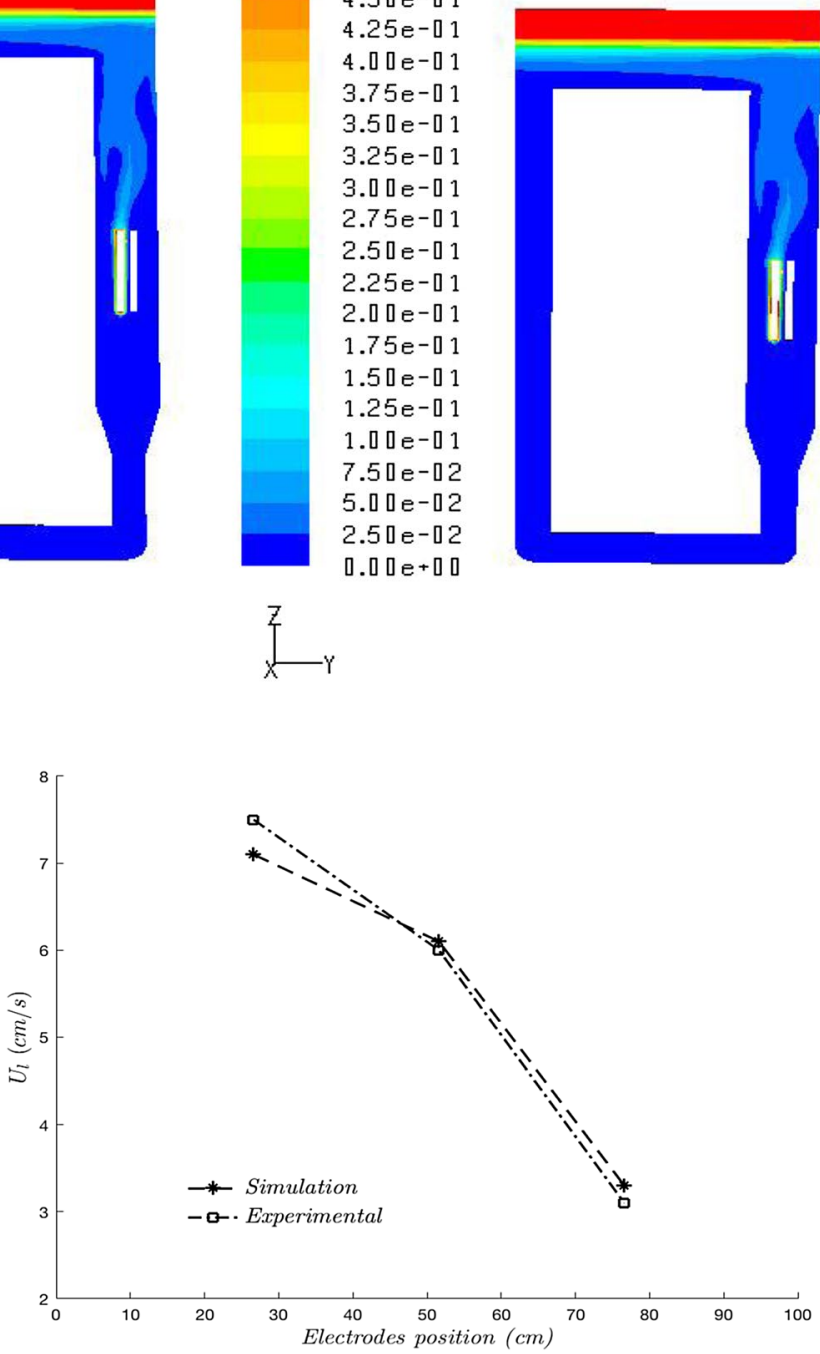

Fig. 11 Evolution of the mean liquid velocity following the electrodes position

configuration. Thus, the lower position in the first configuration induced an overall liquid circulation that produced an erosion of flotation layer in the separator [19]. This constitutes an improvement in reactor performance in the case of batch mode.

The distribution of the gas is presented in Fig. 15. In the steady state, the gas is localized only in the free surface of the reactor. The bubbles do not reach the downcomer which is an advantage for the effluent treatment. Thus, the gas bubbles generated should be used only to float the floc. The average gas holdup is then computed for different values of superficial gas velocities corresponding to different values of current intensities. Table 5 shows that the computations by CFD predict gas holdup values between $0.0065(0.65 \%)$ and $0.072(7.2 \%)$ when current 
Fig. 12 Liquid velocity vector corresponding to three positions of electrodes
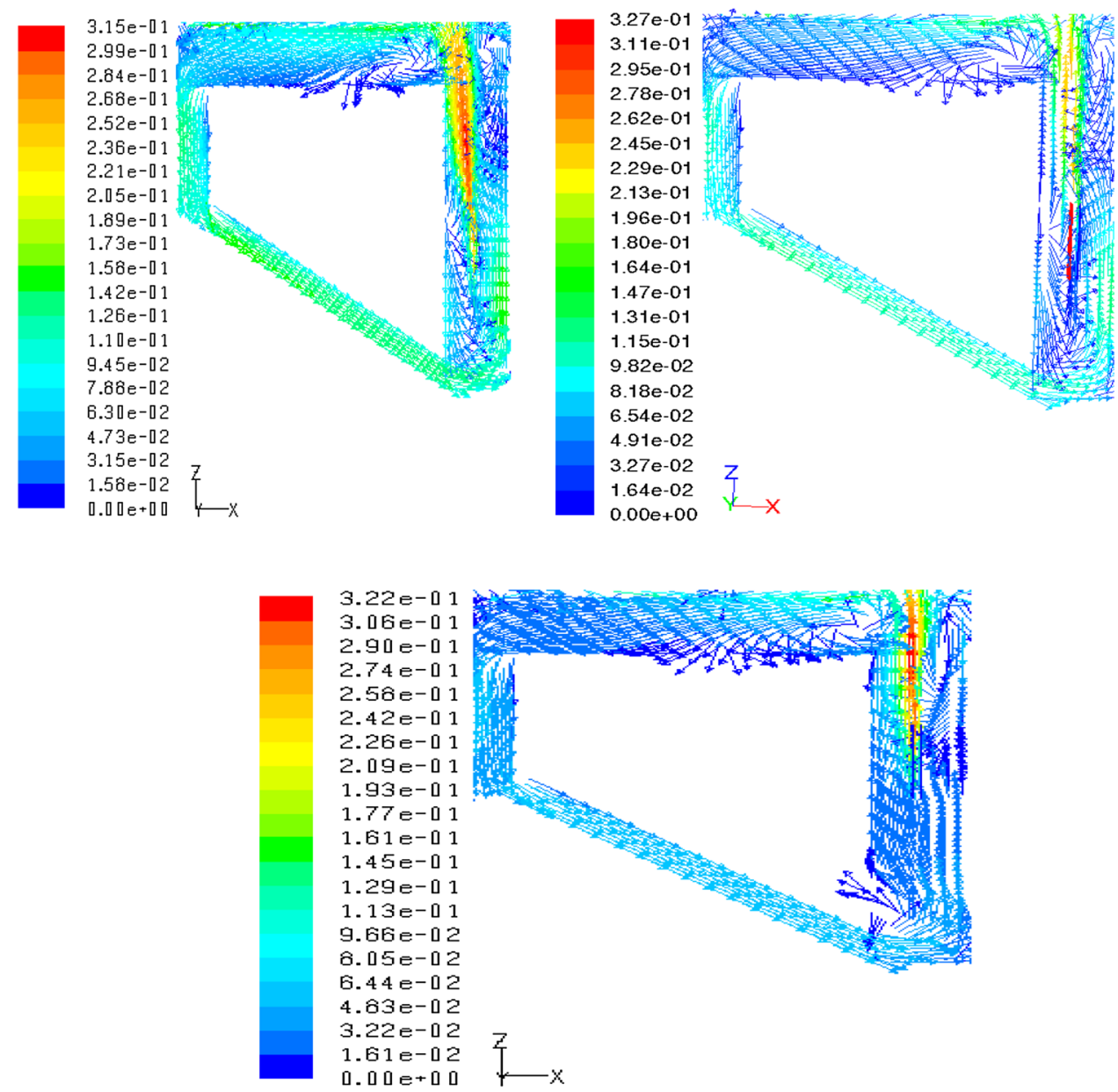

Table 4 Average and maximum liquid velocities according to positions $(\mathrm{I}=2 \mathrm{~A})$

\begin{tabular}{llll}
\hline Electrodes position & Lower & Middle & Upper \\
\hline Average liquid velocity $(\mathrm{m} / \mathrm{s})$ & 0.071 & 0.061 & 0.033 \\
Maximum liquid velocity $(\mathrm{m} / \mathrm{s})$ & 0.312 & 0.311 & 0.309 \\
\hline
\end{tabular}

intensity varied between 1 and $25 \mathrm{~A}$. The corresponding values of average liquid velocity are also represented in Table 5.

Figure 16 shows the evolution of average gas holdup versus current intensity in the case of the middle position of the electrodes. All the next results concerned the middle position of the electrodes. The results obtained for the superficial liquid velocity should be correlated to the average gas holdup. Indeed, the difference in gas holdups in the two compartments $\left(\varepsilon_{\mathrm{d}}\right.$ and $\left.\varepsilon_{\mathrm{r}}\right)$ is a driving force which induces the recirculation of the liquid.

The model based on Chisti's equation $[3,16]$ can be developed to correlate $U_{L d}, h_{D}$ and $j$ (current density $=l$ /
$\mathrm{S}_{\mathrm{e}}$ ). When gas hold-up in the downcomer is negligible, the energy balance model reduces to the following expression:

$\mathrm{U}_{\mathrm{Ld}}=\mathrm{K}\left(\varepsilon_{\mathrm{r}} \mathrm{h}_{\mathrm{D}}\right)^{0.5}$

$\varepsilon_{\mathrm{d}}$ is equal to 0 as suggested by the simulations results and $K$ is a constant.

On the basis of empirical correlations from the literature [27], $\varepsilon_{\mathrm{r}}$ should vary with superficial gas velocity $U_{G r}$ as $U_{G r}^{a}$ with a between 0.5 and 0.6 in external-loop airlift reactors. As gas flow rate is proportional to current, this gives $U_{\mathrm{Ld}} \sim /^{\alpha / 2}$.

Experimental data of $U_{I d}$ (or $U_{\mid l}$ ) has to be presented versus the current density (j). Figure 17 shows the values of the superficial liquid velocity as a function of the current density $\left(j=\mathrm{l} / \mathrm{S}_{\mathrm{e}}\right)$.

The values obtained show that the relationship between $U_{l}$ and $j$ follows the power law with a power coefficient of 0.35 as almost theoretically expected (0.3). CFD provides results which are supported both by the theoretical prediction of the balance of the dissipated energy balance gas in the reactor and the experimental results. The 
Fig. 13 Liquid velocity magnitude in three positions of electrodes
Fig. 14 Photo showing the designed second configuration: the recoverd sludge by electroflotation

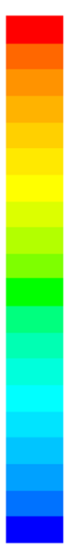

$3.27 e-01$

$3.11 \mathrm{e}-01$ $2.94 \mathrm{e}-\mathrm{0} 1$ $2.78 \mathrm{e}-\mathrm{a} 1$ $2.62 e-01$ $2.45 \mathrm{e}-01$ $2.29 \mathrm{e}-01$ $2.13 e-\square 1$ $1.96 \mathrm{e}-01$ $1.80 \mathrm{e}-01$ $1.63 e-01$ $1.47 \mathrm{e}-01$ $1.31 \mathrm{e}-\mathrm{Q} 1$ $1.14 \mathrm{e}-\mathrm{0} 1$ $9.81 \mathrm{e}-02$ $8.17 \mathrm{e}-02$ $6.54 e-02$ $4.90 \mathrm{e}-02$ $3.27 \mathrm{e}-02$ $1.63 e-02$ $0.00 \mathrm{De}+\mathrm{Qu}$

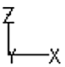

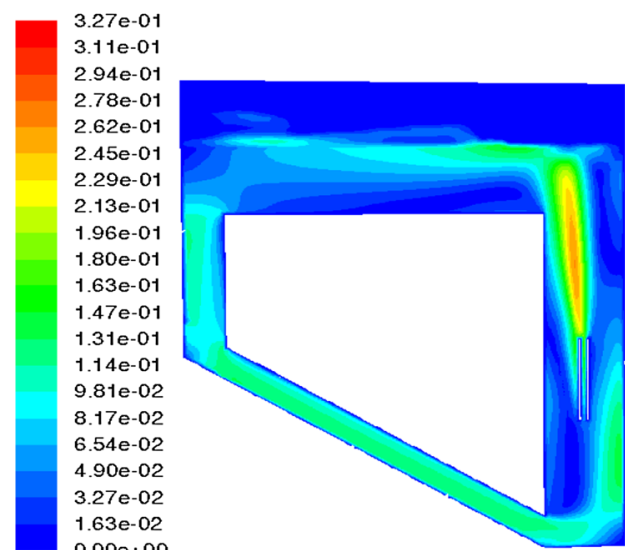

Z

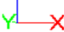

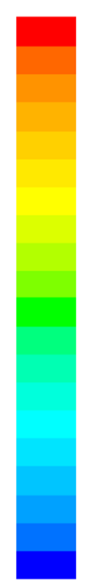

3. $27 e-41$

$3.11 e-01$

$2.94 e-01$

$2.78 e-01$

2. $62 e-01$

$2.45 e-01$

$2.29 e-01$

2. $13 e-01$

$1.96 e-01$

$1.80 e-01$

$1.63 e-01$

$1.47 e-01$

$1.31 e-01$

$1.14 \mathrm{e}-01$

$9.61=-02$

6. $17 e-02$

$6.54 e-02$

$4.90 e-02$

$3.27 e-02$

$1.63 e-02$

$0.00 e+00$
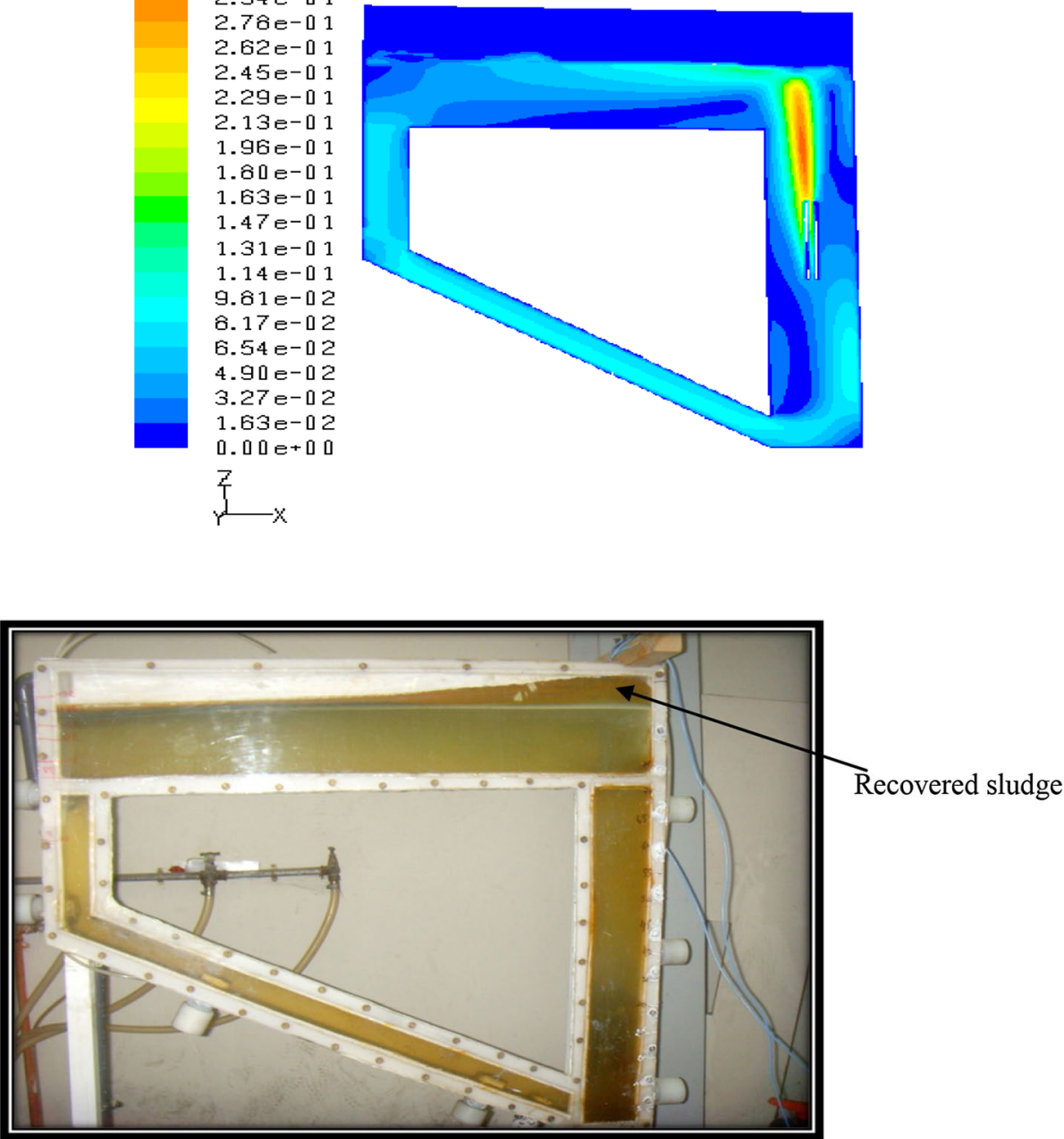

good agreement between predictions, experiments and simulations are illustrated by the fitted parameter $a=0.35$ that is close to the literature [22] in which a is between 0.25 and 0.3 .

\subsubsection{Influence of bubbles diameter}

At this stage, the middle position $(z=51.6 \mathrm{~cm})$ is chosen to study the influence of bubble diameter. The superficial 
Fig. 15 Gas volume fraction for three positions of electrodes
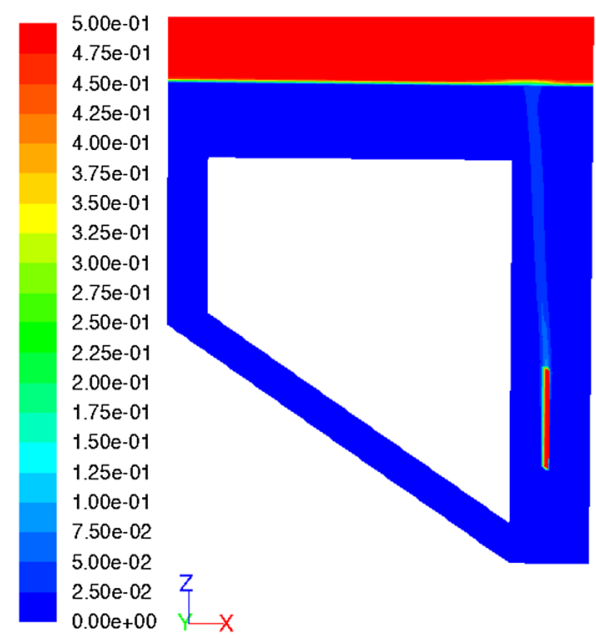

$5.00 e-0$

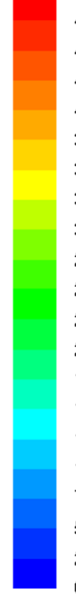
$4.75 \mathrm{e}-01$ $4.50 \mathrm{e}-01$ $4.25 \mathrm{e}-01$ $4.00 e-01$ $3.75 \mathrm{e}-01$ $3.75 \mathrm{e}-01$
$3.50 \mathrm{e}-01$ $3.25 e-01$ $3.00 \mathrm{e}-01$ $2.75 \mathrm{e}-01$ $2.50 \mathrm{e}-01$ 2. $25 e-01$ 2.00e-01 $1.75 \mathrm{e}-01$ $1.50 \mathrm{e}-01$ $1.25 \mathrm{e}-01$ $1.00 \mathrm{e}-0$ $7.50 \mathrm{e}-02$ $5.00 \mathrm{e}-02$ $2.50 \mathrm{e}-02$ $0.00 \mathrm{e}+00 \forall x$

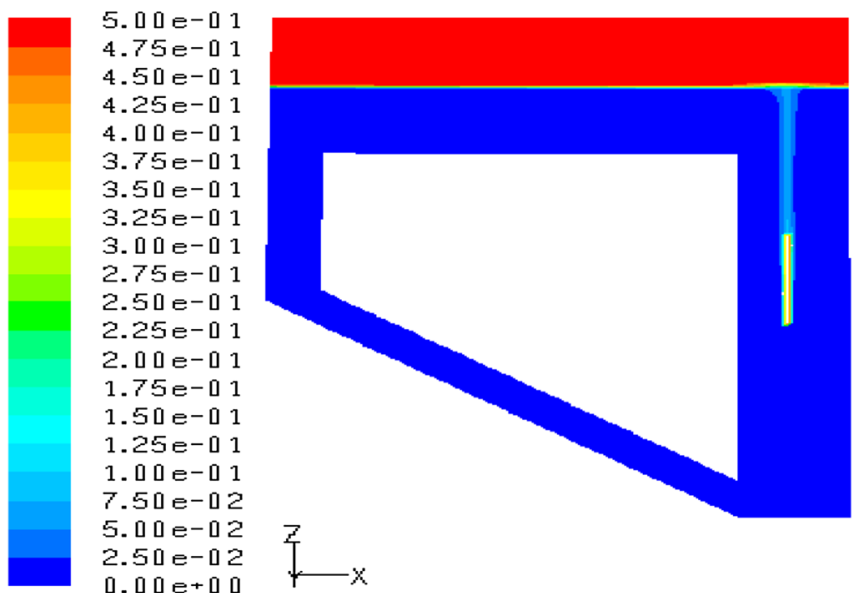

Table 5 Predicted gas hold-up $\left(\varepsilon_{\mathrm{g}}\right)$ and the corresponding average liquid velocity $\left(\mathrm{U}_{\mathrm{l}}\right)$ versus current intensity $(\mathrm{l})$ or current density $(\mathrm{j})$

\begin{tabular}{lllll}
\hline $\mathrm{I}(\mathrm{A})$ & $\mathrm{j}\left(\mathrm{mA} / \mathrm{cm}^{2}\right)$ & $\mathrm{Ug}(\mathrm{cm} / \mathrm{s})$ & $\mathrm{UI}(\mathrm{cm} / \mathrm{s})$ & $\varepsilon_{\mathrm{g}}$ \\
\hline 1 & 5.7 & 0.0007 & 2.1 & 0.0065 \\
5.7 & 32.7 & 0.004 & 5.1 & 0.032 \\
10 & 57 & 0.007 & 5.4 & 0.045 \\
12.85 & 73.5 & 0.009 & 5.6 & 0.049 \\
20 & 114.3 & 0.014 & 6.2 & 0.062 \\
20.85 & 119.2 & 0.015 & 6.3 & 0.065 \\
25 & 142.8 & 0.0175 & 6.8 & 0.07 \\
\hline
\end{tabular}

gas velocity is kept constant. The results of the investigation are represented in Table 6 . It shows that the average liquid velocity increases strongly with the decreases of the bubbles diameter. When bubble diameter decreases from 0.25 to $0.05 \mathrm{~mm}$ the mean velocity of the liquid increases about $7 \%$. However, numerical instabilities were observed in the case of a bubble diameter value lower than $0.05 \mathrm{~mm}$ (Table 6). The experiments in bubble column and airlifit reactor confirmed the simulations results. Thus, the

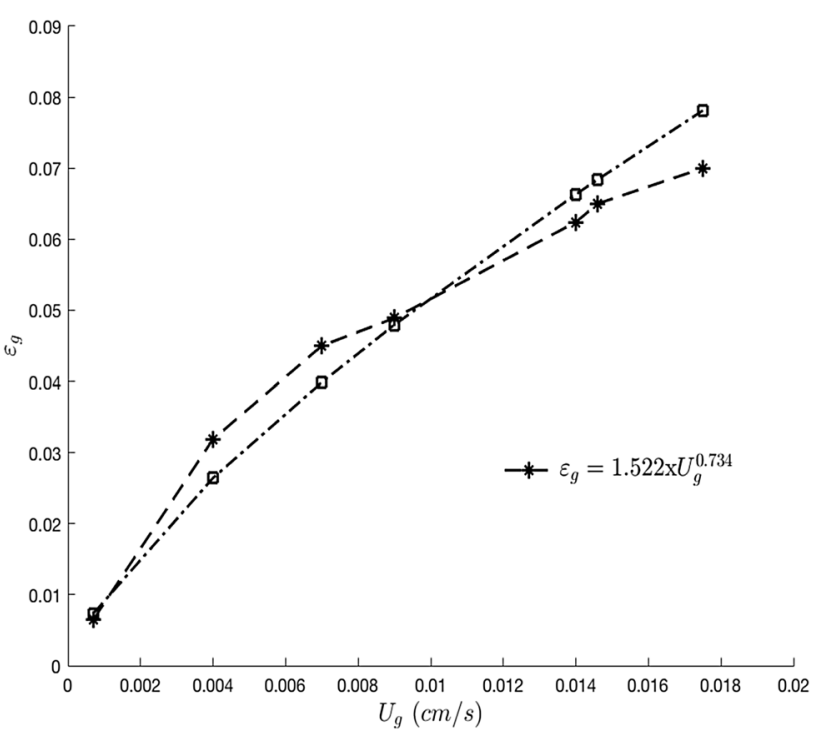

Fig. 16 Gas holdup versus superficial gas velocity $\left(U_{g}=Q_{g} / S_{e}\right)$

\section{SN Applied Sciences}




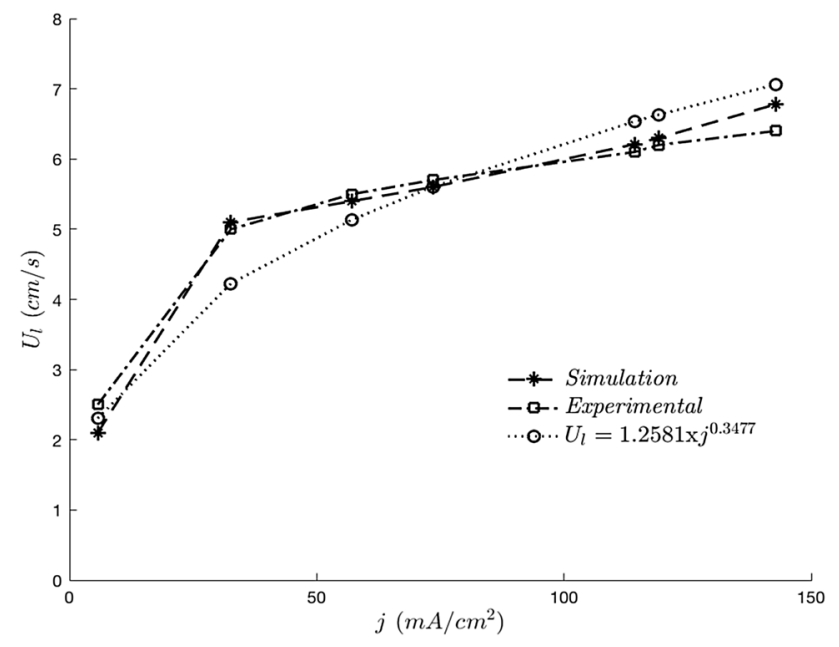

Fig. 17 Superficial liquid velocity versus current density

Table 6 Influence of bubbles diameter on the average liquid velocity

\begin{tabular}{ll}
\hline $\begin{array}{l}\text { Bubble diameter } \\
(\mathrm{mm})\end{array}$ & $\begin{array}{l}\text { Average } \\
\text { liquid } \\
\text { velocity } \\
(\mathrm{cm} / \mathrm{s})\end{array}$ \\
\hline 0.25 & 6 \\
0.2 & 6.2 \\
0.15 & 6.34 \\
0.1 & 6.4 \\
0.05 & 6.43 \\
0.01 & $\begin{array}{l}\text { Numeri- } \\
\text { cal }\end{array}$ \\
& instabil- \\
& ity \\
\hline
\end{tabular}

high viscosity in which coalescence phenomena of bubbles occur. It's known that the high viscosity increases drag forces allowing to more coalescence. Consequently the bubble rise velocity increases leading to a reduction of gas holdup. Consequently the superficial liquid velocity decreases as gas holdup is the driving force for the liquid recirculation.

\subsection{Experimental application}

Treatment of real effluent of disperse dyes was undertaken. Disperse dyes are used on the polyester. Discharges of disperse dyes have characteristics that do not facilitate treatment by electroflotation. These unfavorable parameters are acidity and conductivity of the medium $(\mathrm{pH}=3.8$ and low conductivity, $\mathrm{k}=1.1 \mathrm{mS} / \mathrm{cm}$ ). Hence, the need to adjust these two parameters before treatment is crucial. This adjustment can make the conductive solution and a level of acidity that helps make favorable conditions for EC/EF. As shown in Fig. 18, the asymptotic value of decolourization is reached after an electrolysis time of $45 \mathrm{~min}$. It reached $85 \%$ for wavelength corresponding to $436 \mathrm{~nm}$ whereas the decolourisation efficiency reached $75 \%$ in the case of a wavelength corresponding to $525 \mathrm{~nm}$ and $620 \mathrm{~nm}$. This indicates that kinetics of decolourisation differs according to the component containing in the dye. This result is obtained with a total recovery of the sludge by electroflotation.

increase in bubble diameter induces an increase in bubble rise velocity allowing a decrease in gas holdup in the riser. The high values of bubble diameter simulate the case of

Fig. 18 Evolution of the decolourization efficiency of real textile effluent versus time, $\mathrm{pHi}($ initial $)=6.9, \mathrm{k}=6.5 \mathrm{mS} / \mathrm{cm}$, $\mathrm{j}=31.4 \mathrm{~mA} / \mathrm{cm}^{2}$ )

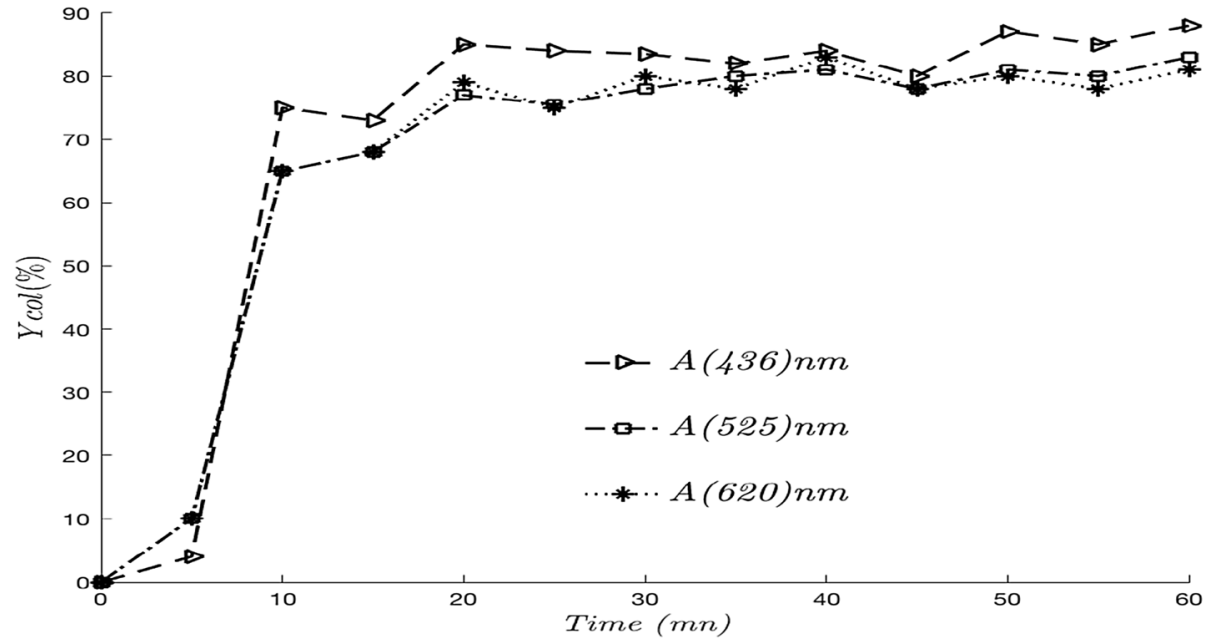

SN Applied Sciences 


\section{Conclusion}

The first challenge of the present paper is the use of CFD to design an innovative reactor to promote a high performance allowing accomplishing the desired efficiency.

The numerical investigation had revealed the importance of current intensity and electrodes position to control the liquid velocity.

The simulations of the first configuration with continuous mode confirmed the experimental results in which only $10-30 \%$ of the main flow crosses the riser section.

The influence of outlet position concerns only the magnitude of liquid velocity: The average liquid velocity decreases slightly as the outlet moves upwards. However, continuous mode results are not improved by the output position.

Concerning the new design of external airlift reactor the main results of the simulations are:

- Average liquid velocity increases when the electrodes are positioned in depth (lower position in the riser) but this position ensures a total flotation of sludge contrarily to the first configuration.

- Average liquid velocity decreases when the bubble diameter increases.

As the filtration process is not needed the cost of electrocoagulation/electroflotation can be lowered.

Preliminary experiments for continuous mode are encouraging (not presented in this article) because $80 \%$ of the main flow crosses the riser section (presence of the electrodes) instead of $30 \%$ of the first configuration. The study of the inlet and the outlet of the reactor are in course to obtain $100 \%$ of the main flow that crosses the riser. This aspect and the use of population balance equations to take into account the bubbles diameter distribution will be the subject of the next paper.

Acknowledgements Sincere thanks are due to Hassan II University of Casablanca for financial help.

\section{Compliance with ethical standards}

Conflict of interest The authors declare that they have no conflict of interest.

\section{References}

1. WHO (2008) Guidelines for drinking-water quality. Third edition incorporating the first and second addenda, Volume 1 recommendations. World Health Organization
2. Ali JH, Ramlah A, Mohd Azlan MI, Lee DW (2016) Adsorption of methylene blue onto activated carbon developed from biomass waste by $\mathrm{H}_{2} \mathrm{SO}_{4}$ activation: kinetic, equilibrium and thermodynamic studies. Desalination Water Treat 25:194

3. Greaves AJ, Phillips DAS, Taylor JA (1999) Correlation between the bioelimination of anionic dyes by an activated sewage sludge with molecular structure. Part 1: literature review. JSDC 115:363-365

4. Chen G, Lei L, Yue PL (1999) Wet oxidation of high concentrated reactive dyes. Ind Eng Chem Res 38:1837-1843

5. Chu W, Ma CW (2000) Quantitative prediction of direct and indirect dye ozonation kinetics. Water Res 34:3153-3160

6. Lin SH, Lai CH (2000) Kinetic characteristics of textile wastewater ozonation in fluidized and fixed activated carbon beds. Water Res 34:763-772

7. Sun G, Xu X (1997) Sunflower stalks as adsorbents for color removal from textile wastewater. Ind Eng Chem Res 36:808-812

8. Mollah MYA, Morkovsky P, Gomes JAG, Kesmez M, Parga JR, Cocke DL (2004) Fundamentals, present and future perspectives of electrocoagulation. J Hazard Mater 114:199-210

9. Naje AS, Chelliapan S, Zakaria Z, Abbas SA (2016) Electrocoagulation using a rotated anode: a novel reactor design for textile wastewater treatment. J Environ Manag 176:34-44

10. Khan SU, Islam DT, Farooqi IH, Ayub S, Basheer F (2019) Hexavalent chromium removal in an electrocoagulation column reactor: Process optimization using CCD, adsorption kinetics and $\mathrm{pH}$ modulated sludge formation. Process Saf Environ Prot 122:118-130

11. Benekos Andreas K, Zampeta Charikleia, Argyriou Rafailia, Economou Christina N, Triantaphyllidou Irene-Eva, Tatoulis Triantafyllos I, Tekerlekopoulou Athanasia G, Vayenas Dimitris V (2019) Treatment of table olive processing wastewaters using electrocoagulation in laboratory and pilot-scale reactors. Process Saf Environ Prot 131:38-47

12. Khorram AG, Narges F (2018) Treatment of textile dyeing factory wastewater by electrocoagulation with low sludge settling time: optimization of operating parameters by RSM. J Environ Chem Eng 6:635-642

13. Pollard DJ, Ison AP, Shamlou PA, Lilly MD (1998) Reactor heterogeneity with saccharopolyspora erythraea airlift fermentations. Biotechnol Bioeng 58(5):453-463

14. Bannari R, Bannari A, Vermette P, Proulx P (2012) A model for cellulase production from trichoderma reesei in an airlift reactor. Biotechnol Bioeng 109(8):2025-2038

15. Chisti Y (1989) Airlift bioreactors. Elsevier, London

16. Chisti Y, Moo-Young M (1987) Airlift reactors: applications and design considerations. Chem Eng Sci 43:451-457

17. Nicolella C, van Loosdrecht M, Heijnen J (1999) Identification of mass transfer parameters in three-phase biofilm reactors. Chem Eng Sci 54(1516):3143-3152

18. Talvy S, Cockx A, Line A (2005) Global modelling of a gas liquid solid airlift reactor. Chem Eng Sci 60(22):5991-6003

19. Essadki AH, Bennajah M, Gourich B, Vial C, Azzi M, Delmas H (2008) Electrocoagulation/electroflotation in an external-loop airlift reactor application to the decolorization of textile dye wastewater: a case study. Chem Eng Process 47(8):1211-1223

20. Balla W, Essadki AH, Gourich B, Dassaa A, Chenik H, Azzi M (2010) Electrocoagulation/electroflotation of reactive, disperse and mixture dyes in an external-loop airlift reactor. J Hazard Mater 184:710-716

21. Essadki AH, Gourich B, Vial C, Delmas H, Bennajah M (2009) Defluoridation of drinking water by electrocoagulation/electroflotation in a stirred tank reactor with a comparative performance to an external-loop airlift reactor. J Hazard Mater 168(23):1325-1333 
22. Essadki AH, Gourich B, Vial C, Delmas H (2011) Residence time distribution measurements in an external-loop airlift reactor: study of the hydrodynamics of the liquid circulation induced by the hydrogen bubbles. Chem Eng Sci 66(14):3125-3132

23. Bannari R, Kerdouss F, Selma B, Bannari A, Proulx P (2011) Mass transfer and shear in an airlift bioreactor: using a mathematical model to improve reactor design and performance. Chem Eng Sci 66(10):2057-2067

24. Nacereddine M, Rachida R, Fatiha B, Jack L (2018) Global hydrodynamic of hybrid external loop airlift reactor: experiments and CFD modeling. Chem Eng Process 129:118-130

25. Xuedong J, Ning Y, Bolun Y (2016) Computational fluid dynamics simulation of hydrodynamics in the riser of an external loop airlift reactor. Particuology 27:95-101

26. Tao Z, Chaohai W, Chunhua F, Yuan R, Haizhen W, Sergei P (2019) Advances in characteristics analysis, measurement methods and modeling of flow dynamics in airlift reactors. Chem Eng Process Intensif 144:107633

27. Burlutskii E, Di Felice R (2019) Experimental and numerical study of two-phase flow mixing in gas-liquid external-loop airlift reactor. Int J Multiph Flow 119:1-13

28. Fukui Y, Yuu S (1985) Removal of colloidal particles in electroflotation. AIChE J 31(2):201-208

29. Pino L, Yepez M, Saez AD (1990) An experimental study of gas holdup in two-phase bubble columns with foaming liquids. Chem Eng Commun 89(1):155-175

30. Shah YT, Joseph S, Smith DN, Ruether JA (1985) On the behavior of the gas phase in a bubble column with ethanol-water mixtures. Ind Eng Chem Process Des Dev 24(4):1140-1148

31. Bannari R, Kerdouss F, Selma B, Bannari A, Proulx P (2008) Threedimensional mathematical modeling of dispersed two-phase flow using class method of population balance in bubble columns. Comput Chem Eng 32(12):3224-3237

32. Weller H (2002) Derivation, modeling and solution of the conditionally averaged two-phase flow equations, Nabla Ld, Technical Report TR/HGW/02

33. Issa R (1986) Solution of the implicitly discretised fluid flow equations by operator-splitting. J Comput Phys 62(1):40-65

34. Jasak H (1996) Error analysis and estimation for the finite volume method with applications to fluid flows. Ph.D. thesis, Department of Mechanical Engineering: Imperial College of Science, Technology and Medicine. University of London

35. Rusche H (2002) Computational fluid dynamics of dospersed two-phase flows at high phase fraction. Ph.D. thesis, Department of Mechanical Engineering: Imperial College of Science, Technology and Medicine. University of London

36. Kerdouss F, Bannari A, Proulx P, Bannari R, Skrga M, Labrecque $Y$ (2008) Two-phase mass transfer coefficient prediction in stirred vessel with a CFD model. Comput Chem Eng 32(8):1943-1955

37. Versteeg $\mathrm{H}$, Malalasekera W (1995) An introduction to computational fluid dynamics. Pearson Education Limited, England

38. Muddle RF, Van Den Akker HEA (2001) 2D and 3D simulations of an internal airlift loop reactor on the basis of a two-fluid model. Chem Eng Sci 56(2122):6351-6358

Publisher's Note Springer Nature remains neutral with regard to jurisdictional claims in published maps and institutional affiliations. 